\title{
Spheroids from equine amnion mesenchymal stem cells: an in vitro study
}

\author{
Alessandra Colia, Maria Rita Stornellia, Francesca Nocchi ${ }^{b}$, Roberta Lamanna ${ }^{b}$, Mariacarla loriob, Simone Lapi ${ }^{b}$,

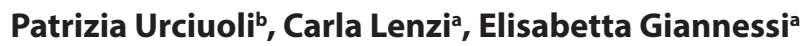

Abstract
Background: Equine amnion mesenchymal stem cells (EAMSCs) from amnion isolated after
the foal birth represented an alternative source of easy collection of mesenchymal cells used in
equine regenerative medicine.
Materials and Methods: These cells grown as two-dimensional (2-D) culture in alpha modified
minimum essential medium supplemented with epidermal growth factor were differentiated in
adipogenic, chondrogenic, and osteogenic cells. Half a million cells as pellet were left in 15 ml
tubes with the same differentiation media for 20 days. After the pellets were collected, embedded
in paraffin for morphological study.
Results: 2 -D culture showed EAMSCs with an embryonic phenotype (C-kit+, CD105+, Oct-4+)
and a differentiation potential in adipogenic, chondrogenic and osteogenic multipotent cells. By
a reproducible method of three-dimensional (3-D) culture, at day 20 the Authors evidenced a
formation of small aggregated spheroids gradually gathering. In cross sections, the surface of the
spheroid evidenced flattened cells embedded in a red matrix by Alizarin staining and occasionally
a core of calcium precipitation. A network of apoptotic or necrotic cells in a not mineralized
matrix was present into the center of nodules. The 3 -D spheroids appeared larger (mean diameter
of $605 \pm 53 \mu$ for gathering spheroids and $1486 \pm 79 \mu$ m for spheroids already gathered) than
those from standard monolayer cultures (mean diameter of $200 \pm 73 \mu \mathrm{m}$ ).
Conclusions: EAMSCs cultured in $3 \mathrm{D}$ method preserve their in vitro multipotent differentiation
than adherent $2-\mathrm{D}$ culture method. These EAMSCs included in the extracellular matrix not
mineralized at day 20 seem to be a good source of MSCs for tissue repair and regeneration in
equine medicine.

Keywords: Equine, Amnion, Mesenchymal stem cells, Cell culture, Spheroid, Immunohistochemistry

\section{INTRODUCTION}

Equine mesenchymal stem cells (EMSCs) were isolated from bone marrow [1-4], adipose tissue [5], peripheral blood [1] and cord blood [6,7]. Currently, there is an increasing interest in the investigation of adult extra-embryonic tissues such as fetal adnexa (amnion, amniotic fluid and Wharton jelly) [8-10] due to easy collection after birth of the foal.

${ }^{\text {aDepartment }}$ of Veterinary Sciences, University of Pisa, Pisa, Italy, ${ }^{b}$ Department of ???, Cell Biology and Tissue Regeneration Laboratory

- Immunohaematology 2 Unit - Azienda Ospedaliero Universitaria Pisana, Pisa, Italy

Correspondence: Alessandra Coli, Department of Veterinary Sciences, University of Pisa, Viale delle Piagge, 2, 56124, Pisa, Italy. Tel.: +390502216856 , webfax: +390502210655 , Email: alessandra.coli@unipi.it

Computing Interest: None declared.

Received: 00-00-000

Accepted: $00-00-000$

Published:00-00-000
Hoyonowski et al. [11] first isolated and characterized mesenchymal stem cells from equine umbilical cord matrix (Wharton's jelly) with an embryonic phenotype (Oct-4, C-kit) and an ability of osteogenic, chondrogenic and adipogenic differentiation. Among the equine fetal adnexa, the amnion has been recently studied as an alternative source of mesenchymal cells used in the field of equine regenerative medicine. The amnion is a thin membrane, which forms the wall of a fluid-filled sac in which the embryo develops. In mammals, the amnion is derived from the inner somatopleure membrane, which remains attached to the embryo at the umbilicus. In literature, it is reported that mesenchymal cells can be isolated from amnion. They express stem cell surface markers such as embryonic stem cells and are doubly negative for MHC I and MHC II [12]. They can differentiate into ectodermal and endodermal lineages once isolated and grown in special culture media [13]. These cell populations display a fibroblast-like appearance, adhere onto plastic culture vessels, form clonal colonies and under appropriate culture conditions, they differentiate into adipocytes, osteocytes, chondrocytes and neuronal cells [1417]. Therefore, these cells represent a potential use in cellular therapy and regenerative medicine applications. The Authors 
have already performed a procedure of expanding equine amnion mesenchymal stem cells (EAMSCs) by a non-invasive technique for the isolation of the cells and used culture media supplemented with epidermal growth factor (EGF) $[15,16]$.

In addition to traditional two-dimensional (2-D) culture methods in which the mesenchymal stem cells grow in a single layer, in recent years many authors suggest the use of three-dimensional (3-D) culture. As the plastic surface limits the potential of stem cells to recreate in-vivo conditions [18], aggregates of cells grown in suspension culture and showing a spheroid shape are reported. They can be embedded in scaffolds [19-22] or cultivated scaffold-free $[23,24]$ though it is reported that a synthetic material may represent a limitation to the cell-cell interactions $[25,26]$.

These spheroids ("mesenspheres") show a physiological microenvironment in which cell-cell or cell-scaffold interactions are better achieved than in monolayer culture methods $[23,27]$. If grown in appropriated culture media, these spheroids exhibit chondrogenic, adipogenic and osteogenic competence and an enhanced secretion of tropic factors [28-30].

\section{Objective}

The aim of this study is to perform an efficient and reproducible method for the isolation of EAMSCs and their differentiation into spheroids, reporting on adipogenic, chondrogenic and osteogenic differentiation in terms of morphological and morphometrical point of view, in order to obtain a biological source with potential clinical use in regenerative medicine of horses.

\section{MATERIALS AND METHODS}

Amnion cells were obtained from 410 to 13 years old standardbred mares as previously described [16]. For the study of cellular stemness, immunocytochemistry on amnion sections with anti-C-Kit, -CD105 and -Oct-4 antibodies, involved selfrenewal of embryonic stem cells, was performed as reported above [16]. Amnion samples, washed in phosphate-buffered saline (PBS) solution (Euroclone, MI, Italy) and soaked in $10 \mathrm{~mL}$ of a collagenase solution $(1 \mathrm{mg} / \mathrm{mL})$ for $30 \mathrm{~min}$ at $37^{\circ} \mathrm{C}$, were suspended and filtered through a $100 \mathrm{~mm}$ filter (Millipore, Billerica, MA, USA).

\section{2-D Cell Culture}

Nucleated cells isolated by gradient centrifugation (500 g for $10 \mathrm{~min}$ ) were resuspended in Alpha modified minimum essential medium ( $\alpha$-MEM) (Cambrex, NJ, USA) with $10 \%$ fetal bovine serum (Eurobio, France), 10\% horse serum (HS), 100 $\mathrm{U} / \mathrm{mL}$ penicillin, $100 \mu \mathrm{g} / \mathrm{mL}$ streptomycin, $2 \mathrm{mM}$ L-glutamine (Euroclone, MI, Italy) and $10 \mathrm{ng} / \mathrm{ml}$ EGF (Sigma). Cells were cultured at $10^{5} \mathrm{cells} / \mathrm{cm}^{2}$ and the adherent ones were grown in fresh medium for about 14 days, until $90 \%$ of confluence (Passage 0, or P0). For further expansion (Passage 1, or P1) the cells were then sub-cultured (by $0.25 \%$ trypsin in $1 \mathrm{mM}$ ethylenediaminetetraacetic acid [EDTA]) (Euroclone, Milan, Italy) for $5 \mathrm{~min}$ at $37^{\circ} \mathrm{C}$, replated at 5000 cells $/ \mathrm{cm}^{2}$ and harvested with the same protocol.

\section{3-D Cell Culture}

Half a million cells were dissociated with $0.25 \%$ trypsin in 1 mM EDTA (Euroclone, Milan, Italy), centrifuged at $1000 \mathrm{rpm}$ for $5 \mathrm{~min}$ and the pellet was left in $15 \mathrm{ml}$ tubes in a rotary shaker in an incubator with the differentiation media (adipogenic, chondrogenic and osteogenic media) for 20 days. Every 3 days, the tubes with the cells were centrifuged at $1000 \mathrm{rpm}$ for $5 \mathrm{~min}$, the supernatant removed and replaced with fresh medium. After 20 days, the pellets were collected and washed in PBS.

\section{Flow Cytometric Study}

Analysis was performed, as mentioned above, [16] using anti-MHC I (Serotec, Oxford, UK), anti-MHC II (Serotec), antiCD14 (Serotec), anti-CD45 (Serotec), anti-CD44 (Chemicon, Temecula, CA, U.S.A.), anti-b-1-integrin (Chemicon) and anti-CD90 (Santa Cruz Biotechnology, Santa Cruz, CA, U.S.A.) mouse monoclonal antibodies. As secondary antibody, an FITC goat anti-mouse IgG (Santa Cruz Biotechnology) was used. A minimum of 10.000 events was acquired for each sample.

\section{Differentiation protocols}

Adipogenic medium: a-MEM supplemented with 10\% FCS and $10 \% \mathrm{HS}, 100 \mathrm{U} / \mathrm{mL}$ Penicillin, $100 \mu \mathrm{g} / \mathrm{mL}$ Streptomycin, 12 $\mathrm{mM}$ L-glutamine, $5 \mu \mathrm{g} / \mathrm{mL}$ insulin (Lilly), $50 \mu \mathrm{M}$ indomethacin (Sigma), $1 \mathrm{mM}$ dexamethasone (Sigma, St.Louis, MO, U.S.A.) and $0.5 \mu \mathrm{M}$ 3-isobutyl-1-methylxanthine (IBMX, Sigma, St.Louis, MO, U.S.A.) for 2 weeks.

Chondrogenic medium: Chondrocyte basal medium (Cambrex Bio Science, Walkersville, MD, U.S.A.) for 3 weeks.

Osteogenic medium: a-MEM supplemented with $10 \%$ FCS and $10 \% \mathrm{HS}, 100 \mathrm{U} / \mathrm{mL}$ penicillin, $100 \mu \mathrm{g} / \mathrm{mL}$ streptomycin, $2 \mathrm{mM}$ L-glutamine, $20 \mathrm{mM}$ b-glycerol phosphate (Sigma, St.Louis, MO, U.S.A), $100 \mathrm{nM}$ dexamethasone (Sigma, St.Louis, MO, U.S.A.) and $250 \mu \mathrm{M}$ ascorbate 2-phosphate (Sigma, St.Louis, MO, U.S.A) for 3 weeks.

\section{Histology}

Cell monolayer (2-D cell culture) was fixed in 10\% formalin for $20 \mathrm{~min}$ at RT and stained with $0.5 \%$ Oil Red O (Sigma, St. Louis, MO, U.S.A.) in methanol (Sigma) for $20 \mathrm{~min}$ at RT, Alcian Blue solution (Sigma, St. Louis, MO, U.S.A.) pH 2.5 for 20 min at RT (cell nuclei counterstained with Weigert's iron hematoxylin) and Alizarin Red (Sigma, St. Louis, MO, U.S.A.) $\mathrm{pH} 4.1$ for $20 \mathrm{~min}$ at RT.

The spheroids from 3-D culture were fixed in $10 \%$ formalin for $20 \mathrm{~min}$ at reverse transcription (RT) and embedded in 
paraffin. They were sectioned at $4 \mu$, made permeable with methanol for $2 \mathrm{~min}$ at RT and washed 3 times with PBS. The sections were processed by Alizarin Red and by double staining (Alcian blue and Alizarin Red).

\section{Morphometry}

The size of spheroids was measured by Nikon Digital Sight DS-U1 Program (Nikon)

\section{RESULTS}

Amnion sections showed positivity for C-Kit, CD105 and Oct-4 antigens, markers of stemness (Figure 1). Cytofluorimetric analysis of EAMSCs showed cells positive to CD 90, CD 44, CD 14 and CD 45.

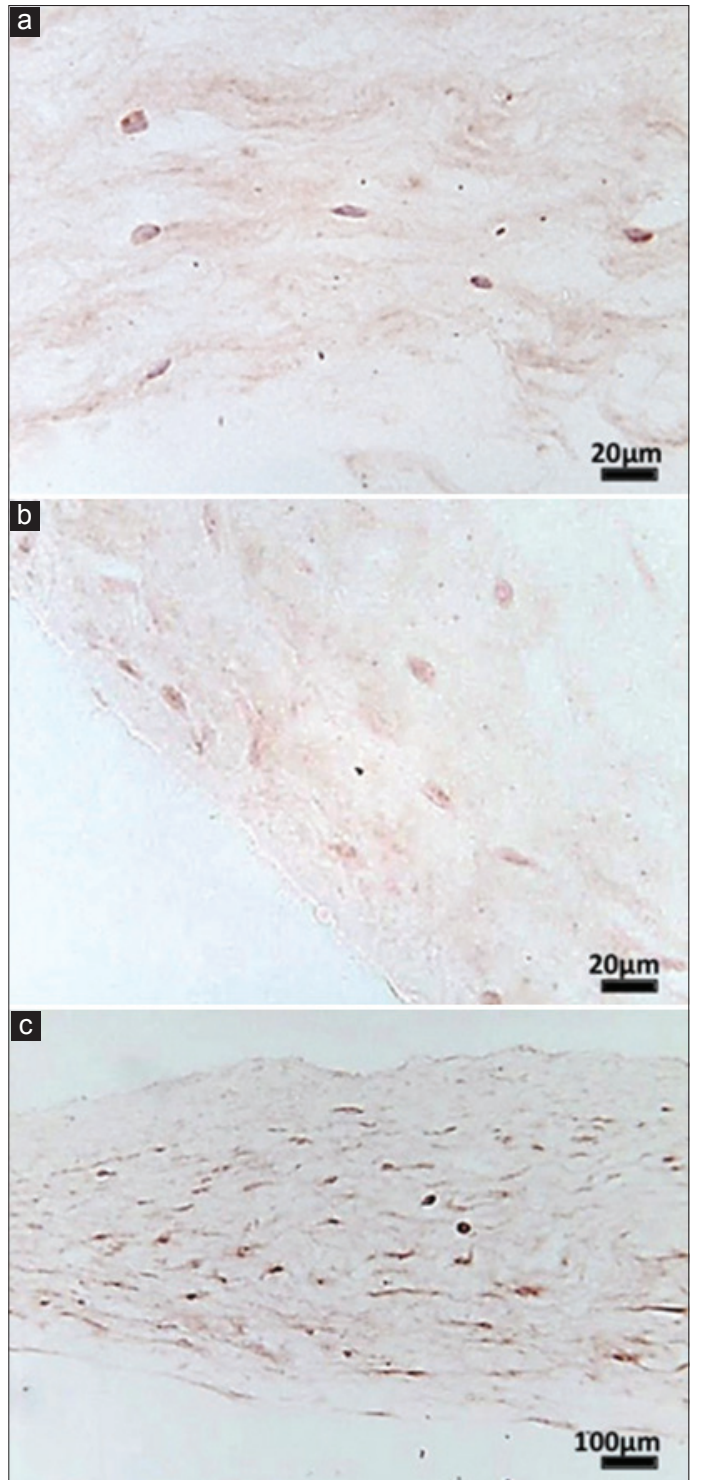

Figure 1: Immunohistochemical study: C-Kit (a), CD105 (b) and Oct4 (c) antigens
In 2-D cell culture adipogenic differentiation showed 1 rounded cells staining positive with Oil Red $\mathrm{O}$, with 2 lipid vesicles in the cytoplasm increasing in amount over 3 time (Figure 2a). Chondrogenic differentiation showed glycosaminoglycans in the matrix after alcian blue staining (Figure 2b). With osteogenic differentiation, from the $5^{\text {th }}$ day of cell culture, the Authors observed bone nodules $(200 \pm 73 \mu \mathrm{m}$ of mean diameter) with a layer of epithelium-like fibroblastoid cells around, close to each other, more elongated and flattened (Figure $2 \mathrm{c}$ and $\mathrm{d}$ ).

Histological analyses of 3-D cell culture (Figure 3) after 20 days of culture showed nodules aggregated in small spheroids that gradually gathered into a single one (Figure $3 \mathrm{a}$ ). Epithelial cells of spheroid surface, embedded in a red matrix by Alizarin staining, were observed. In every single small nodule it was possible to observe epithelium-like fibroblastoid cells and a network of apoptotic or necrotic cells embedded into a

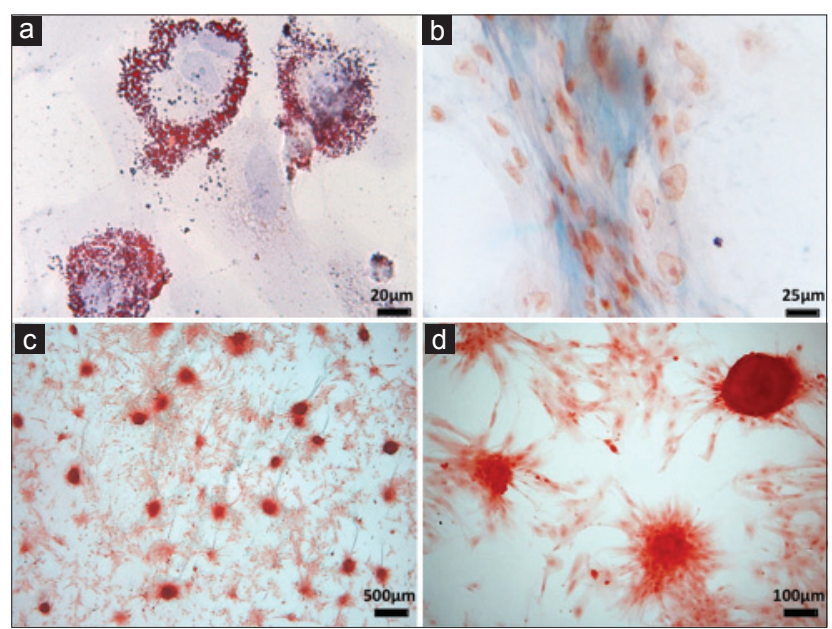

Figure 2: EAMSCs in 2-D culture: adipogenic (oil red O) (a), chondrogenic (alcian blue) (b) and osteogenic (alizarin red) (c and d) differentiation

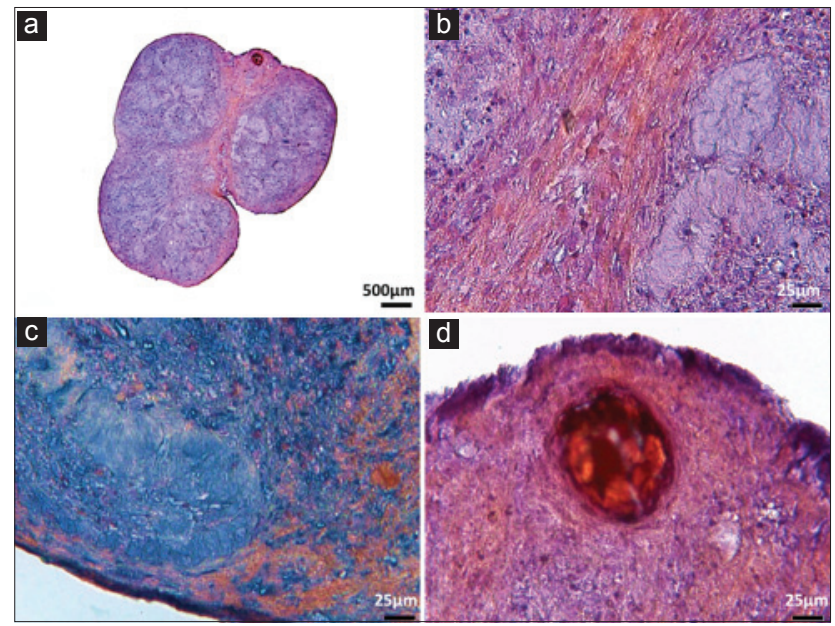

Figure 3: Equine amnion mesenchymal stem cells differentiation in 3-D culture spheroid sections: Alizarin red ( $\mathrm{a}, \mathrm{b}$ and $\mathrm{d}$ ); alcian blue and alizarin red (c) 
non-mineralized matrix, organized in circular or ovoid areas, positive to Alcian blue staining, (Figure $3 \mathrm{~b}$ and $\mathrm{c}$ ). Where the matrix was mineralized, it was possible to highlight a core of calcium precipitation (Figure 3d). The 3-D spheroids appeared larger than those from standard monolayer cultures: Their mean diameter ranged from $605 \pm 53 \mu \mathrm{m}$ for single spheroids getting together to $1486 \pm 79 \mu \mathrm{m}$ for spheroids already gathered in a single one.

\section{DISCUSSION}

In the literature are present studies about equine mesenchymal cells from other sources but not from amnion $[6,10]$. The EAMSCs were investigated for their possible use in cell therapy because of non-invasive techniques for cell extraction; indeed, it was easy to sample amnion immediately after birth because the colt come off the chorion and the mare second the rest of the placenta later. Bacterial and fungal contamination represented the main problem to be settled, due to the environment where the procedure of amnion sampling was performed. For this purpose we used a sampling protocol employed in our previous study [15] Cytofluorimetric analysis showed a phenotype of mesenchymal stem cells, confirming the positivity of stemness antigens and thus their pluripotency.

When grown in specific culture media, EAMSCs differentiated into adipogenic, chondrogenic and osteogenic lineages. The effects of the addition of EGF in the culture medium did not affect their ability to differentiate [15]. This study developed a technique for sampling, isolation and expansion of EAMSCs for producing a 3-D cell culture system. The method of aggregation for EAMSCs spheroid formation yielded largely homogeneous spheroids, which might be maintained for a longer time (20 days) in suspension by rotary shaking. Under chondrogenic conditions the Authors showed the presence of glycosaminoglycans as blue deposits immersed in a network of fibroblastoid cells, as reported in literature for bovine umbilical cord [24] but of larger diameter for they gathered in a single spheroid. Under osteogenic conditions a significant positive staining of flattened cells suggesting their osteogenic differentiation was observed, even if the mineralization of nodule matrix was not complete at 20 days (as reported by double staining). By both of the staining methods, the Authors observed changes in cell morphology, especially for the cells embedded in the matrix, referred to as different replicative ability [18]. From literature, 3-D cell culture systems allowed a more physiological environment for stem cells survival in contrast to adherent monolayer; cell-cell and cell-matrix interactions improved. The matrix mineralization increased until day 14 of osteogenic differentiation for murine bone marrow-derived MSCs [23] and until day 10 for human bone marrow-derived MSCs [22]

\section{CONCLUSIONS}

Our data showed that at 20 days of osteogenic differentiation matrix mineralization is not yet complete (extracellular matrix was positive to alcian staining and negative to alizarin red staining). The Authors referred this difference to the embryonic origin of these cells; their self-renewal and high potential of sub-culturing in vitro might be greater than adult MSCs. This study confirmed the successful development of 3-D culture method for EAMSCs in preserving their in-vitro multi-potent differentiation than the adherent 2-D culture method. These results might provide a basis for the establishment of a database for collecting and preserving EAMSCs to be used for equine regenerative medicine.

\section{REFERENCES}

1. Koerner J, Nesic D, Romero JD, Brehm W, Mainil-Varlet P, Grogan SP. Equine peripheral blood-derived progenitors in comparison to bone marrow-derived mesenchymal stem cells. Stem Cells 2006;24:1613-9.

2. Vidal MA, Kilroy GE, Lopez MJ, Johnson JR, Moore RM, Gimble JM. Characterization of equine adipose tissue-derived stromal cells: adipogenic and osteogenic capacity and comparison with bone marrow-derived mesenchymal stromal cells. Vet Surg 2007;36:613-22.

3. Arnhold SJ, Goletz I, Klein H, Stumpf G, Beluche LA, Rohde C, et al. Isolation and characterization of bone marrow-derived equine mesenchymal stem cells. Am J Vet Res 2007;68:1095-105.

4. Kisiday JD, Kopesky PW, Evans CH, Grodzinsky AJ, McIlwraith CW, Frisbie DD. Evaluation of adult equine bone marrow- and adiposederived progenitor cell chondrogenesis in hydrogel cultures. J Orthop Res 2008;26:322-31.

5. Vidal MA, Kilroy GE, Johnson JR, Lopez MJ, Moore RM, Gimble JM. Cell growth characteristics and differentiation frequency of adherent equine bone marrow-derived mesenchymal stromal cells: adipogenic and osteogenic capacity. Vet Surg 2006;35:601-10.

6. Koch TG, Heerkens T, Thomsen PD, Betts DH. Isolation of mesenchymal stem cells from equine umbilical cord blood. BMC Biotechnol 2007;7:26.

7. Reed SA, Johnson SE. Equine umbilical cord blood contains a population of stem cells that express Oct4 and differentiate into mesodermal and endodermal cell types. J Cell Physiol 2008;215:329-36.

8. Secco M, Zucconi E, Vieira NM, Fogaça LL, Cerqueira A, Carvalho MD, et al. Mesenchymal stem cells from umbilical cord: Do not discard the cord! Neuromuscul Disord 2008;18:17-8.

9. Marcus AJ, Woodbury D Fetal stem cells from extra-embryonic tissues: do not discard. J Cell Mol Med 2008;12:730-42.

10. Lovati AB, Corradetti B, Lange Consiglio A, Recordati C, Bonacina E, Bizzaro D, et al. Comparison of equine bone marrow-, umbilical cord matrix and amniotic fluid-derived progenitor cells. Vet Res Commun 2011;35:103-21.

11. Hoynowski SM, Fry MM, Gardner BM, Leming MT, Tucker JR, Black L, et al. Characterization and differentiation of equine umbilical cord-derived matrix cells. Biochem Biophys Res Commun 2007;362:347-53.

12. Kobayashi M, Yakuwa T, Sasaki K, Sato K, Kikuchi A, Kamo I, et al. Multilineage potential of side population cells from human amnion mesenchymal layer. Cell Transplant 2008;17:291-301.

13. Miki T, Strom SC. Amnion-derived pluripotent/multipotent stem cells. Stem Cell Rev 2006;2:133-42. 2 3 4 5 6 7 8 9 
14. Kim J, Lee Y, Kim H, Hwang KJ, Kwon HC, Kim SK, et al. Human amniotic fluid-derived stem cells have characteristics of multipotent stem cells. Cell Prolif 2007;40:75-90.

15. Passeri S, Nocchi F, Lamanna R, Lapi S, Miragliotta V, Giannessi $\mathrm{E}$, et al. Isolation and expansion of equine umbilical cord-derived matrix cells (EUCMCs). Cell Biol Int 2009;33:100-5.

16. Coli A, Nocchi F, Lamanna R, Iorio M, Lapi S, Urciuoli P, et al. Isolation and characterization of equine amnion mesenchymal stem cells. Cell Biol Int Rep (2010) 2011;18:e00011.

17. Violini S, Gorni C, Pisani LF, Ramelli P, Caniatti M, Mariani P. Isolation and differentiation potential of an equine amnion-derived stromal cell line. Cytotechnology 2012;64:1-7.

18. Saleh FA, Frith JE, Lee JA, Genever PG. Three-dimensional in vitro culture techniques for mesenchymal stem cells. Methods Mol Biol 2012;916:31-45.

19. Yang XB, Bhatnagar RS, Li S, Oreffo RO Biomimetic collagen scaffolds for human bone cell growth and differentiation. Tissue Eng 2004;10:1148-59.

20. Zhao F, Grayson WL, Ma T, Bunnell B, Lu WW. Effects of hydroxyapatite in 3-D chitosan-gelatin polymer network on human mesenchymal stem cell construct development. Biomaterials 2006;27:1859-67.

21. Markusen JF, Mason C, Hull DA, Town MA, Tabor AB, Clements M, et al. Behavior of adult human mesenchymal stem cells entrapped in alginate-GRGDY beads. Tissue Eng 2006;12:821-30.

22. Cerwinka WH, Sharp SM, Boyan BD, Zhau HE, Chung LW, Yates C. Differentiation of human mesenchymal stem cell spheroids under microgravity conditions. Cell Regen (Lond) 2012;1:2.

23. Baraniak PR, McDevitt TC. Scaffold-free culture of mesenchymal stem cell spheroids in suspension preserves multilineage potential. Cell Tissue Res 2012;347:701-11.

24. Cardoso TC, Ferrari HF, Garcia AF, Novais JB, Silva-Frade C, Ferrarezi MC, et al. Isolation and characterization of Wharton's jelly-derived multipotent mesenchymal stromal cells obtained from bovine umbilical cord and maintained in a defined serum- free three-dimensional system. BMC Biotechnol 2012;12:18.

25. Wang W, Itaka K, Ohba S, Nishiyama N, Chung UI, Yamasaki Y, et al 3D spheroid culture system on micropatterned substrates for improved differentiation efficiency of multipotent mesenchymal stem cells. Biomaterials 2009;30:2705-15.

26. Jing Y, Jian-Xiong Y 3-D spheroid culture of bone marrow mesenchymal stem cell of rhesus monkey with improved multidifferentiation potential to epithelial progenitors and neuron in vitro. Clin Experiment Ophthalmol 2011;39:808-19.

27. Baraniak PR, Cooke MT, Saeed R, Kinney MA, Fridley KM, McDevitt TC. Stiffening of human mesenchymal stem cell spheroid microenvironments induced by incorporation of gelatin microparticles. J Mech Behav Biomed Mater 2012;11:63-71.

28. Baraniak PR, McDevitt TC. Stem cell paracrine actions and tissue regeneration. Regen Med 2010;5:121-43.

29. Bartosh TJ, Ylöstalo JH, Mohammadipoor A, Bazhanov N, Coble K, Claypool K, et al. Aggregation of human mesenchymal stromal cells (MSCs) into 3D spheroids enhances their antiinflammatory properties. Proc Natl Acad Sci U S A 2010;107:13724-9.

30. Frith JE, Thomson B, Genever PG. Dynamic three-dimensional culture methods enhance mesenchymal stem cell properties and increase therapeutic potential. Tissue Eng Part C Methods 2010;16:735-49.

(C) 2015 Coli et al. licensee El Med J. This is an open access article distributed under the terms of the Creative Commons Attribution License, which permits unrestricted use, distribution, and reproduction in any medium, provided the original work is properly cited.

Cite this article as: Coli A, Stornelli MR, Nocchi F, Lamanna R, Lorio M, Lapi S, Urciuoli P, Lenzi C, Giannessi E. Spheroids from equine amnion mesenchymal stem cells: an in vitro study. El Med J 2015, 3(1):1-5

DOI: ${ }^{* * *}$
Author Queries???

AQ1: Kindly provide running tilte

AQ2: Kindly provide department

AQ3: Kindly provide history details

AQ4: Embryonic stem cells are surface markers?

AQ5: I dont get this

AQ6: Meaning unclear 7 